\title{
Design and Development of Training System for Teaching on Blast Furnace Mechatronics
}

\author{
Ye Sun*, Ren Chen, Zuoliang Zhang, Meng Li, Yan Liu, Mingxia Feng, Huishu Zhang and Yan Cui \\ Department of Metallurgy Engineering, Liaoning Institute of Science and Technology, 117004, Benxi, China \\ *Corresponding author
}

\begin{abstract}
Based on the practical teaching requirements of metallurgical engineering, a cold position training device on blast furnace was designed in line with actual production. The control system adopts the integrated control cabinet and its design of the training device is implemented by the PLC of Siemens S7-300 and the configuration software of Real Bridge. The control mode includes two kinds of modes, which are remote control and manual control. Through the development and use of blast furnace training devices, the teaching content can be visualized. This device has been put into use in colleges, and obtained the good training effect.
\end{abstract} system

Keywords-blast furnace; mechantronics system; plc control

\section{INTRODUCTION}

Metallurgical engineering is a major of strong engineering practicality, which is needed to improve the comprehensive analysis and the ability to use in practice. However, the ferrous metallurgical production process is a continuous industrial processes, and the process parameters are not allowed to change in the actual production process. So students do not achieve good effects by factory practice. In addition, students can not have the opportunity to practice by themselves in the practical process by taking safety and other factors into consideration. And it leads theory teaching to divorce from practice work. To make up the deficiencies of practical teaching and promote understanding of the professional foundation knowledge and metallurgical processes as well as equipments for students, developing related equipment for metallurgical technology training, creating realistic production environment of metallurgy process, enhancing the understanding of ferrous metallurgy production process for students and the engineering practice and innovation ability, are the basis to ensure the quality of course teaching[1]. Thus, we developed some practice teaching models of metallurgical engineering and blast furnace training device is one of the series of teaching model.

\section{THE PRODUCTION PROCESS OF THE BLAST FURNACE}

Blast furnace is a continuous production process to reduce iron ore into pig iron. A generation of the blast furnace (from blow in to overhaul blowing out) can last a few years to a few decades. In production, iron ore, coke, and flux are loaded into furnace from the top (the furnace top usually is composed of bell and hopper and the modern blast furnace has bell valve top and non-bell top) continuously and hot air $\left(1000-1300^{\circ} \mathrm{C}\right)$ is blown and oil, coal, natural gas or other fuels are injected from the tuyere of the blast furnace bottom. The iron ore into the blast mainly is compounds of iron and oxygen. At high temperatures, the carbon of the coke and the injection material and carbon monoxide from carbon combustion can capture the oxygen from the iron ore to get iron and this process is called reduction. Molten iron is released from the taphole. The gangue in the iron ore and the ash in the coke and injection material are combined with the flux of limestone to generate slag, which is discharged from cinder notch. The coal gas exporting from the top of the furnace can be used as industrial gas after dedusting. Modern blast furnace can also use the high pressure of the top to generate electricity with the exporting gas.

\section{The Blast Furnace Training Device}

The blast furnace training device was produced according to a 1:20 ratio of the actual blast furnace, mainly including five parts of the main body of the furnace, distributing device, spiral ejector, charge recycling bins and base platform. The main body of the furnace is a semicircle structure, the upper part of which has air outlets and a number of pressure measurement points in the observation plane and the lower part of which has round hot blast pipes connecting the external the gas source and the gas tank through the gas flowmeter. And the main body of the furnace has 14 tuyeres. The base platform is located in the lower part of the main body of the furnace. The spire ejectors are installed in the location of feed tube corresponding to the each tuyere. Each spine ejector is connected to the motor and is controlled by it. The motor will connect the frequency converter and control the feed speed. The feed in the tuyere is to simulate the coke combustion consumption in the actual production. The other end of the spine ejector connects the charge recycling bins located in the base platform. The bottom of the furnace is a controllable and adjustable screw base to simulate the actual production of iron. Figure I is the training device of the blast furnace process.

\section{Control System Of The Training System}

The control system uses mechatronics control cabinet, in which the computer system, frequency converter, PLC, circuit breakers and contactors are mounted. The control buttons are installed in the faceplate of the control cabinet. The computer's serial ports are connected to the PLC's MPI interface via the connecting cable. 
The control mode includes two modes, remote manual control and local manual control. The remote manual control is operated by the operator via the HMI operator interface. The local manual control is operated by the buttons in the control box to control all the motors and valves on the scene.

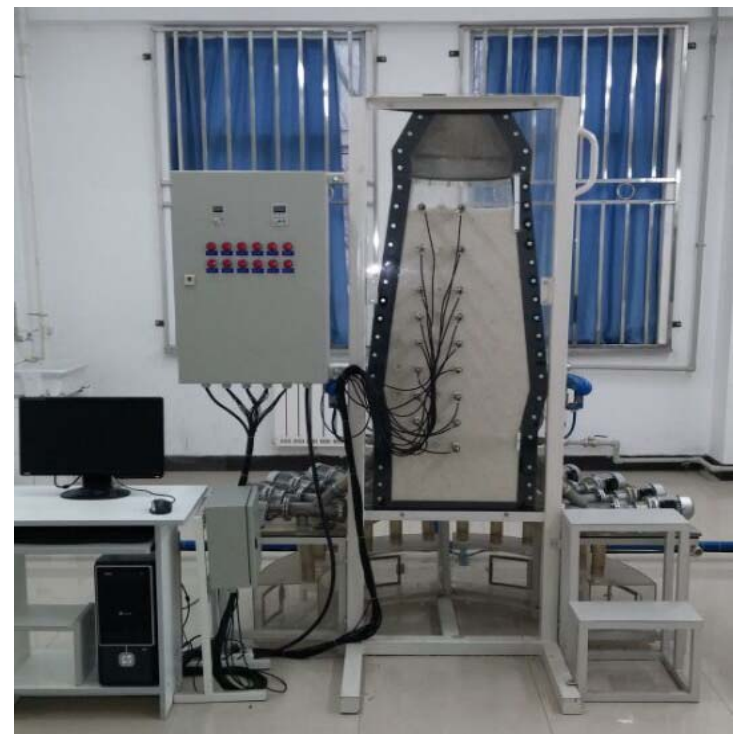

FIGURE I. TRAINING DEVICE OF THE BLAST FURNACE PROCESS

The ECI control system is integrated modular unit of four layers. There are indicator lights of fault display corresponding to each motor in the front of the control carbinet. There are a total control and data displayer in the bottom of the indicator lights. There is a keyboard which can be pulled out below the displayer. When you perform an experiment, you should make sure all the circuit breakers in the carbinet are closed firstly, then connect to the external power and open the circuit breakers sequentially from left to right and from top to bottom lastly. If there is no exception appeared, the power indicator light will work. When the display screen is in normal standby state and there is no alarm and fault indication each part, the experiment can be carried out.

\section{Software Design Of The Training System}

The design adopts cost-effective homemade Real Bridge configuration software, which will be combined with PLC control system for secondary development. The configuration design can complete the remote manual of the entile production process, while the data can be collected and managed in real time. All operations can be completed by the pulled keyboard below the display screen and the built-in touchpad mouse. There are the operating virtual buttons of all components of the system and the corresponding striking indication in the display screen. When clicking on the device of the corresponding portion, it can be run according to our requirements. The production process and equipment operating parameters of the blast furnace of the whole process of the production line can display in the blast furnace process flow diagram, main screen of the blast furnace system, motor control system screen, flow detection system screen and pressure detection system screen. Parameters of the production process can be modified in the corresponding parts of the screen through the keyboard. All the collected and operational data during the experiment will be recorded in real time by the mouse and keyboard. The data can be saved in any location of the hard disc. Figure II is the main interface of the blast furnace training system. Figure III is the control interface of the data collection and run tendency system of the blast furnace. Figure IV is the control interface of the inquiry system of the data collection of the blast furnace. Figure $\mathrm{V}$ is the control interface of the grouping drawing system of the data collection of the blast furnace.

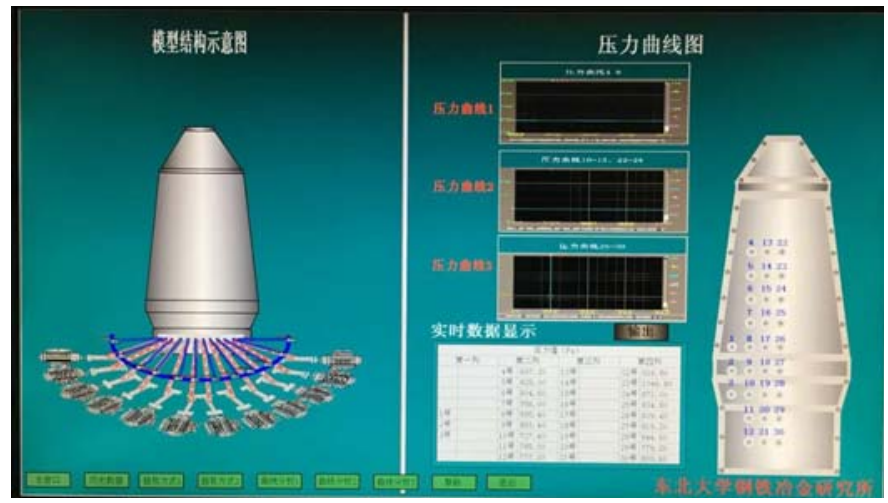

FIGURE II MAIN INTERFACE OF THE BLAST FURNACE TRAINING SYSTEM

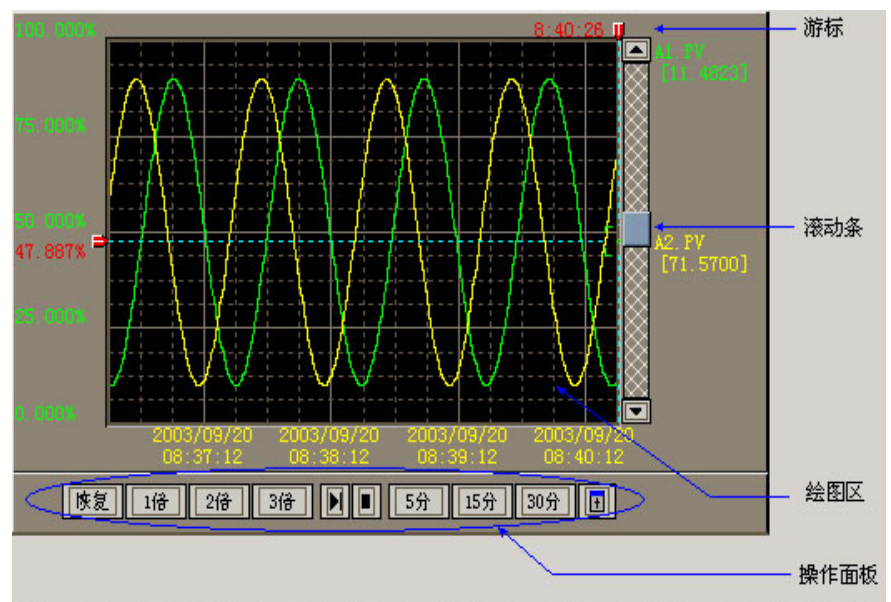

FIGURE III CONTROL INTERFACE OF THE DATA COLLECTION AND RUN TENDENCY SYSTEM OF THE BLAST FURNACE

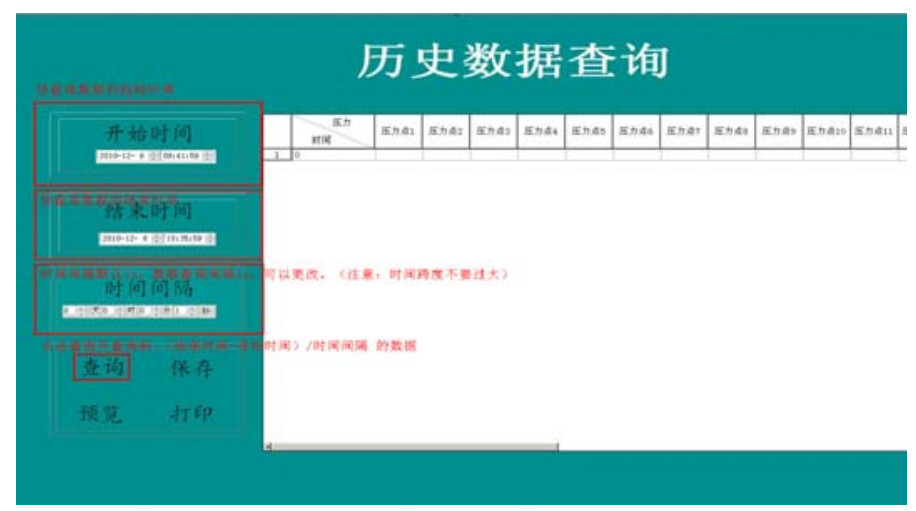


FIGURE IV THE CONTROL INTERFACE OF THE INQUIRY SYSTEM OF THE DATA COLLECTION OF THE BLAST FURNACE

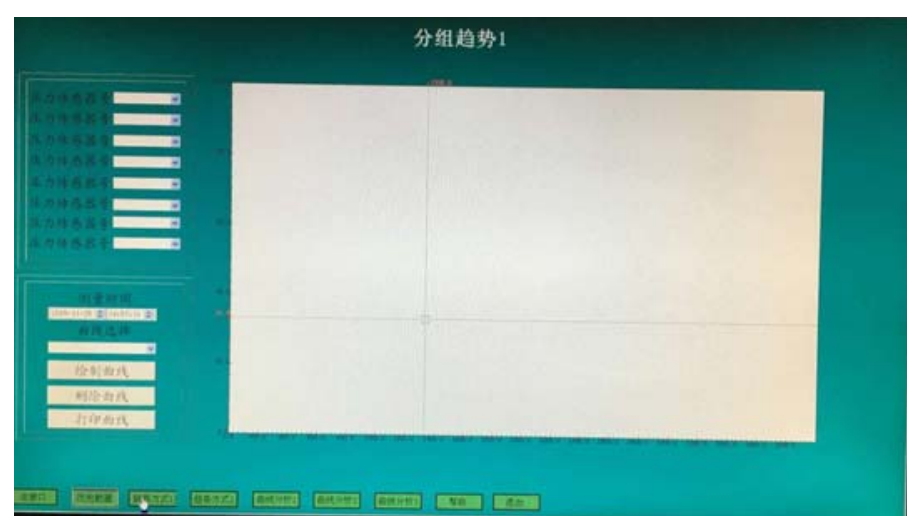

FIGURE V THE CONTROL INTERFACE OF THE GROUPING DRAWING SYSTEM OF THE DATA COLLECTION OF THE BLAST FURNACE

\section{CONCLUSIONS}

Through the development and use of the blast furnace training devices, the teaching content can be visualized and the distance between the classroom and the practice can be narrowed. This device has been put into use for one year, and obtains the good teaching effect. The system has the following characteristics in practical teaching:

(1) Applicability: The practical teaching system with its intuitive form can make students fully understand the production process and improve the timeliness of the teaching. The deficiencies of the field work which is allowed to see and not to try can be made up by establishing realistic simulation environment.

(2) Comprehensiveness: Practical teaching system with computer modeling technique, powder-jet technology, mechanical transmission, motor drive technology and pneumatic conveying technology can achieve the integrated practice teaching of ferrous metallurgy process and operation, sensor, pneumatic technology, PLC control technology, electrical control system, mechanical system installation, motor drive technology, system maintenance, fault detection technology and configuration monitoring technology.

(3) Flexibility: Practical teaching system can fit ferrous metallurgy, mechanics, automation, computer and other majors, which can meet the requirements of the practice training segment of understanding practice, production practice and graduation practice for students. Therefore, there is strong flexibility and more widely adaptability. On the other hand, not only the test can be appointed at any time, but also the impact on production by the operating conditions and the program changes can be experienced in the training process. It can enable students to deepen the understanding of the practice knowledge.

(4) Security: Because of the complexity of the iron and steel metallurgy production process and the high degree of the continuity, there are security risks at any time and anywhere. Students will inevitably face security problems when they enter the site to study and practice. Practice teaching system provides a secure platform for teachers and students to learn and practice. Teaching tasks can be completed in a more relaxed environment.

(5) Practicability: Metallurgical engineering graduates, who are cultivated by the existing teaching mode, have poor perceptual knowledge for actual operation. So the factories often take a lot of time, effort and cost to retrain them. However, it makes teaching follow by the actual production by using practical teaching system to enable students to conduct necessary training operation to obtain practical skills.

\section{ACKNOWLEDGMENT}

The research funded by Liaoning Province Education Administration (No.L2014506) and Doctor Startup Fund of Liaoning Institute of Science and Technology (No.1406B12) and Education Project of Liaoning Institute of Science and Technology.

\section{REFERENCES}

[1] X. G. Wang, J. F. Liu, J. G. Lu, "Design and realization of control system for heat transfer training device," Automation \& Instrumentation, vol. 12, 2000, pp. 37-41 